\title{
The US-Preexposure Effect in Lithium-Induced Flavor-Aversion Conditioning Is a Consequence of Blocking by Injection Cues
}

\author{
Isabel de Brugada \\ University of Granada
}

\author{
Geoffrey Hall and Michelle Symonds \\ University of York
}

\begin{abstract}
In 2 experiments, rats received flavor-aversion conditioning in which the unconditioned stimulus (US) was an orally consumed solution of lithium chloride $(\mathrm{LiCl})$. The resulting aversion was not attenuated by giving preexposure to injections of $\mathrm{LiCl}$, although such preexposure did attenuate aversions established using injected $\mathrm{LiCl}$ as the US (Experiment 1). This outcome suggests that blocking by injection-related cues is responsible for the US-preexposure effect observed in this situation. Experiment 2 confirmed this interpretation by showing that presenting such cues (by giving an injection of saline) at the time that the $\mathrm{LiCl}$ was drunk resulted in an attenuation of conditioning in animals preexposed to injections of $\mathrm{LiCl}$. The US-preexposure effect obtained in these experiments can be explained solely in terms of blocking by injection cues, although other mechanisms may contribute to the effect seen in other flavor-aversion paradigms.
\end{abstract}

For some conditioning procedures, the development of conditioned responding is retarded in animals that have been given prior exposure to the event to be used as the unconditioned stimulus (US). This effect (known as the US-preexposure effect) is well established for the training procedure used in the experiments to be reported here-flavor-aversion conditioning with lithium-induced nausea as the US (for reviews, see Randich \& LoLordo, 1979; Riley \& Simpson, 2001). Two possible mechanisms have been proposed, but neither is wholly satisfactory as an explanation for the effect that is observed in the flavor-conditioning paradigm.

One possibility is that the US-preexposure effect is a consequence of habituation. But although there is evidence to suggest that this process may be important for other USs (see General Discussion), direct study of the unconditioned responses (URs) elicited by the injection of lithium chloride $(\mathrm{LiCl})$ provide no evidence of the occurrence of habituation in this case. Thus, Batson (1983) found no reduction in the ability of $\mathrm{LiCl}$ to evoke a lowered activity level and a hypothermic response over the course of a series of injections. Similarly, Brugada, González, and Cándido (2003a) found that the enhancement of neophobia produced by an injection of $\mathrm{LiCl}$ (Domjan, 1977) was not diminished in rats given preexposure to this treatment. Both of these studies, how-

Isabel de Brugada, Faculty of Psychology, University of Granada, Granada, Spain; Geoffrey Hall and Michelle Symonds, Department of Psychology, University of York, York, United Kingdom.

This work was supported by La Dirección General de Investigación Cientifico y Técnica Project PB98-1362 and by grants from the Wellcome Trust, the Junta de Andalucía, and Plan Proprio de la Universidad de Granada. We thank Juan Pinilla for experimental assistance.

Correspondence concerning this article should be addressed to Isabel de Brugada, Faculty of Psychology, University of Granada, Campus de Cartuja, 18071 Granada, Spain, or to Geoffrey Hall, Department of Psychology, University of York, York YO10 5DD, United Kingdom. E-mail: dbrugada@ugr.es or g.hall@psych.york.ac.uk ever, were able to demonstrate a marked retardation of subsequent conditioning in the animals that had been given preexposure. We can maintain the view that the US-preexposure effect is a consequence of habituation only if it is supposed that those properties of $\mathrm{LiCl}$ that allow it to function as a reinforcer might undergo habituation when the URs studied by Batson and by Brugada et al. (2003a) do not (see Braveman \& Jarvis, 1978).

The second possible interpretation is that US preexposure allows the formation of an association between the US and the context; if the same contextual cues are present during the formal conditioning phase of the procedure, they might then act to block acquisition of the strength by the experimenter's conditioned stimulus (CS). This proposal also has problems, if the critical cues are taken to be those that define the physical context (i.e., the cage) in which preexposure is given. It is well established that a perfectly robust US-preexposure effect can be obtained when all of the experimental procedures (initial exposure to the effects of lithium injections and subsequent flavor-aversion conditioning) are carried out in the animal's home cage (e.g., Brugada, González, \& Cándido, 2003b). In these circumstances, the contextual cues will have undergone extensive latent inhibition training, making it implausible to assume that they could acquire sufficient associative strength during the preexposure phase to block acquisition of strength by the flavor in the conditioning phase. A second issue arises from the fact that the magnitude of the conditioned response (CR) controlled by the conditioned flavor is tested in the same context as that used for training, that is, in the presence of the putative blocking cues. In the standard blocking paradigm (Kamin, 1969), the failure of the blocked cue to control a strong CR is evident only when that cue is tested in isolation - the compound of the blocked cue and blocking cue is fully capable of evoking the CR. On the face of things, therefore, there is no reason to expect that the flavor CS will evoke only a weak CR when it is experienced in the presence of the pretrained contextual cues. To explain the US-preexposure effect in these terms requires us to adopt the 
unsupported assumption that the associative strength acquired by the contextual cues is capable of blocking acquisition of strength by the flavor CS but not of summating with that strength when it comes to performance of the CR.

An alternative version of the blocking interpretation of the US-preexposure effect (first proposed by Rudy, Iwens, \& Best, 1977) lays emphasis on the role of the handling and other cues that are associated with the administration of an intraperitoneal injection. Although the cues that constitute the environmental context of preexposure may have suffered latent inhibition, these injectionrelated cues are novel and uniquely predict the nausea that follows the injection. It is to be expected, therefore, that these cues would readily acquire associative strength. Because they are present on the conditioning trials with the flavor CS, they could act to block acquisition by that CS, and because they are absent on the test trial (when consumption of the conditioned flavor is measured), there is no reason to think that they ought to obscure the true level of aversion governed by that flavor. This interpretation receives support from the observation that procedures designed to restrict the acquisition of associative strength by injection cues can attenuate the US-preexposure effect. Thus, Willner (1978) found that rats given saline injections intermixed with the $\mathrm{LiCl}$ injections during preexposure showed a reduced US-preexposure effect (but see also Braveman, 1978). Further, Brugada and Aguado (2000; see also Brugada et al., 2003b) have demonstrated an attenuation of the effect in rats given a series of saline injections between the US preexposure phase and the conditioning phase. In this case, the saline injections will allow extinction of the association of these cues with nausea and thus reduce their ability to produce blocking.

The role of injection cues has also been assessed by changing the route by which the US is administered from the preexposure to the conditioning phase. Domjan and Best (1980) gave rats preexposure to $\mathrm{LiCl}$ administered by intraperitoneal injection, but in the conditioning phase they gave the $\mathrm{LiCl}$ US by infusion through an intraperitoneal cannula. For these animals, the effect was found to be attenuated (compared with animals for whom the US was also given by injection). This result supports the view that injection cues play a role. That the effect was not entirely abolished may mean either that some other process contributes to the effect or that the cues associated with the infusion were sufficiently similar to those associated with injection that generalization between them allowed some degree of blocking to occur. What is needed is a procedure in which the $\mathrm{LiCl}$ used as the US can be administered in the complete absence of cues like those associated with the injections given during preexposure. The experiments to be reported here explore a technique that makes this possible.

If thirsty rats are given access to a solution of $\mathrm{LiCl}$, they will drink it once; thereafter they will refuse it (and will also refuse other salty solutions, such as a solution of $\mathrm{NaCl}$ ). Loy and Hall (2002) investigated this effect and demonstrated it to be a consequence of associative learning in which the nausea induced by consuming the $\mathrm{LiCl}$ solution establishes an aversion to its salty taste. (The effect was exactly comparable in magnitude with the aversion produced by giving an intraperitioneal injection of an equivalent quantity of $\mathrm{LiCl}$ to rats that had just consumed a saline solution.) This phenomenon makes it possible to investigate the effects of preexposure to lithium (administered by injection) on the aversion produced by drinking a lithium solution (i.e., in the complete absence of handling and other injection-related cues). If blocking by injection cues is the sole source of the US-preexposure effect in this situation, then the aversion to saline produced by drinking $\mathrm{LiCl}$ should be as strong as that obtained in animals given no preexposure.

\section{Experiments $1 \mathrm{a}$ and $1 \mathrm{~b}$}

The design of Experiment 1a is summarized at the top of Table 1. In the preexposure phase, rats in the LI-LO (LI: lithium by injection and LO: lithium taken orally) group received three intraperitoneal injections of $\mathrm{LiCl}$, the exact procedures being those that

Table 1

Experimental Designs

\begin{tabular}{lllllll}
\hline Group & Preexposure & Cond 1 & UR test & CR Test 1 & Cond 2 & CR Test 2 \\
\hline
\end{tabular}

Experiment 1a

\begin{tabular}{llllll} 
LI-LO & $3 \mathrm{LiCl}$ inj & Drink LiCl & $\mathrm{HCl}$ & Sal & Suc-LiCl inj \\
SI-LO & $3 \mathrm{Sal}$ inj & Drink LiCl & $\mathrm{HCl}$ & Sal & Suc-LiCl inj \\
SI-SO & $3 \mathrm{Sal}$ inj & Drink sal & $\mathrm{HCl}$ & Sal & Suc-LiCl inj \\
\hline
\end{tabular}

Experiment $1 \mathrm{~b}$

\begin{tabular}{lllll} 
LI-LO & $3 \mathrm{LiCl}$ inj & Drink A-drink Li & A & B-LiCl inj \\
SI-LO & $3 \mathrm{Sal}$ inj & Drink A-drink Li & A & B-LiCl inj \\
SI-SO & $3 \mathrm{Sal}$ inj & Drink A-drink sal & A & B-LiCl inj \\
\hline
\end{tabular}

Experiment 2

$\begin{array}{llll}\text { LI-LO } & 3 \mathrm{LiCl} \text { inj } & \text { Drink A-drink LiCl } & \text { A } \\ \text { LI-SI/LO } & 3 \mathrm{LiCl} \text { inj } & \text { Drink A-(sal inj)-drink LiCl } & \text { A } \\ \text { SI-SI/LO } & 3 \mathrm{Sal} \text { inj } & \text { Drink A-(sal inj)-drink LiCl } & \text { A }\end{array}$

Note. In Experiment $1 \mathrm{~b}, \mathrm{~A}$ and $\mathrm{B}$ were solutions of vinegar and saccharin (counterbalanced). In Experiment 2, A was saccharin. $\mathrm{L}=$ lithium; $\mathrm{S}=$ saline; $\mathrm{I}=$ injected; $\mathrm{O}=$ oral administration; Cond = conditioning trial; $\mathrm{UR}=$ unconditioned response; $\mathrm{CR}=$ conditioned response; LiCl $=$ lithium chloride; inj $=$ injection; $\mathrm{HCl}=$ hydrochloric acid; $\mathrm{sal}=$ saline; suc $=$ sucrose. 
we have previously shown (Brugada et al., 2003a, 2003b) to produce a robust US-preexposure effect in orthodox flavoraversion conditioning. In this experiment, however, no injection was given on the conditioning trial; rather, the rats were allowed to drink a small quantity of a solution of LiCl. CR Test 1 (see Table 1) assessed the extent to which this treatment established an aversion to the salty taste of a solution of $\mathrm{NaCl}$ (saline). Comparison was made with two control groups. The SI-LO (SI: saline by injection) group received the same conditioning and test procedures but no preexposure to $\mathrm{LiCl}$, receiving instead three injections of isotonic saline in the preexposure phase. The SI-SO (SO: saline taken orally) group also received injections of saline during preexposure but drank $\mathrm{NaCl}$ rather than $\mathrm{LiCl}$ in the next phase. On the basis of the results of Loy and Hall (2002), subjects in the SI-LO group can be expected to show an aversion to the $\mathrm{NaCl}$ solution on test and thus drink less than subjects in the SI-SO group. Subjects in the LI-LO group might also be expected to show an aversion; the question of interest was the extent to which their preexposure treatment might attenuate this aversion.

In addition to testing the effect of preexposure to $\mathrm{LiCl}$ (by injection) on the aversion established by drinking $\mathrm{LiCl}$, we also attempted to assess the effect of such preexposure on the magnitude of the UR evoked by lithium consumption. As we have already noted, an immediate effect of the injection of $\mathrm{LiCl}$ is enhanced neophobia. Pilot work established that consumption of $\mathrm{LiCl}$ evokes the same response-when given access to a novelflavored solution, rats that had just consumed a small amount of $\mathrm{LiCl}$ were found to be less likely to drink the novel solution than rats that had just drunk an equivalent amount of $\mathrm{NaCl}$. Accordingly, immediately after the conditioning trial (Conditioning trial 1 in Table 1), all animals were given access to a novel sour solution (of weak hydrochloric acid, $\mathrm{HCl}$ ). We expected that the LI-LO and SI-LO groups, having just drunk $\mathrm{LiCl}$, would drink less $\mathrm{HCl}$ than rats in the SI-SO group; but if preexposure to injections of $\mathrm{LiCl}$ reduces the magnitude of the neophobic UR, we might expect to find that the suppression of consumption would be less marked in the LI-LO group than in the SI-SO group.

Finally, to confirm the effectiveness of our preexposure procedure as a means of producing the orthodox US-preexposure effect, we administered conditioning to all subjects in which a consumption of a novel sucrose solution was followed by an intraperitoneal injection of $\mathrm{LiCl}$. We anticipated that this procedure would establish less of an aversion in the preexposed group (LI-LO group) than in the control groups. It may be noted that this comparison of the two ways of administering the US is confounded with a difference in the CS to which the aversion is acquired-making use of the fact that drinking lithium will establish an aversion to its salty taste made it necessary to use saline as the test flavor in assessing the aversion established by this procedure (and to use another flavor to assess the effects of the injected US). In Experiment $1 \mathrm{~b}$, we attempted to eliminate this problem by counterbalancing the flavors used as the CS in the two cases. Loy and Hall (2002) have shown that rats that drink a solution of $\mathrm{LiCl}$ presented in compound with another flavor (sucrose, in their experiments) will develop an aversion to the other flavor. We made use of this technique in the present experiment. In the first conditioning phase, the animals received Flavor A (see the central panel of Table 1) prior to drinking $\mathrm{LiCl}$; in the second, they received Flavor $\mathrm{B}$ prior to an injection of $\mathrm{LiCl}$. The substances used as A and B were counterbalanced. In other respects, the design of the experiment was the same as that of Experiment 1a. If we find a US-preexposure effect with Flavor B but not with Flavor A, we may conclude that the presence or absence of the effect depends on the route by which the $\mathrm{LiCl}$ was administered, not on the nature of the flavor used as the CS.

\section{Method}

Subjects and apparatus. The subjects in Experiment 1a were 24 experimentally naive male hooded Lister rats, approximately 3 months old at the start of the experiment. They were housed in individual home cages with continuous access to food. Access to water was restricted as described below. These cages were made of opaque white plastic and measured 35 $\mathrm{cm} \times 22 \mathrm{~cm} \times 19 \mathrm{~cm}$. They had a roof of wire mesh that held food and (when available) a water bottle; a layer of wood shavings covered the floor. The cages were kept in a colony room that was lit from 8:00 a.m. to 8:00 p.m. each day. All experimental treatments were given in these cages during the light period of the illumination cycle. The subjects for Experiment $1 \mathrm{~b}$ were 24 female Wistar rats with a mean weight at the start of the experiment of $204 \mathrm{~g}$. They had previously served in a study of avoidance learning but were naive to the stimuli and procedures used in the present experiment. They were housed in individual home cages that measured 50 $\mathrm{cm}$ long $\times 26 \mathrm{~cm}$ wide $\times 14.5 \mathrm{~cm}$ high. Other details of housing and maintenance were the same as described for Experiment 1a.

Fluids were administered at room temperature in $50-\mathrm{ml}$ plastic centrifuge tubes fitted with stainless steel ball-bearing tipped spouts. Fluid consumption was measured by weighing the tubes before and after presentation. The fluids used were solutions of $\mathrm{LiCl}(0.15 \mathrm{~mol}), \mathrm{NaCl}(0.15$ $\mathrm{mol})$, sucrose $(5 \% \mathrm{wt} / \mathrm{vol}), \mathrm{HCl}(0.01 \mathrm{~mol})$. In addition, a $0.1 \%(\mathrm{wt} / \mathrm{vol})$ solution of sodium saccharin, and a $2 \%(\mathrm{wt} / \mathrm{vol})$ solution of a locally obtained cider vinegar were used in Experiment 1b. For half of the animals in each of the experimental groups of that experiment (see Table 1), vinegar served as Flavor A and saccharin as Flavor B; for the remaining animals, the arrangement was reversed.

Procedure. A schedule of water deprivation was initiated by removing the standard water bottles overnight. On each of the next 3 days, water was made available at noon for a period of $30 \mathrm{~min}$. Throughout the rest of the experiment, either water or a flavored solution was presented at this time; water was also made available for $30 \mathrm{~min}$ from 5:00 p.m. each day.

On the first day of the preexposure phase (see Table 1), rats in the LI-LO groups received an intraperitoneal injection of $4 \mathrm{ml}$ of $\mathrm{LiCl}$ at 11:00 a.m.; subjects in the control groups received an injection of $4 \mathrm{ml}$ of saline at this time. The next day was a recovery day on which the rats were allowed access to water at the standard times, noon and 5:00 p.m. This 2-day cycle was repeated three times. On the day after the final recovery day (Conditioning trial 1 in Table 1), the LI-LO and SI-LO groups of Experiment 1a were given access to $4 \mathrm{ml}$ of the $\mathrm{LiCl}$ solution for $5 \mathrm{~min}$ at noon; the SI-SO group received access to $4 \mathrm{ml}$ of saline at this time. This was followed after 10 min by the neophobia test (the UR test in the table) in which all subjects were given access to $30 \mathrm{ml}$ of $\mathrm{HCl}$ for $30 \mathrm{~min}$. After a recovery day, the aversion to saline was tested by giving the animals a 30-min presentation of the $\mathrm{NaCl}$ solution (CR Test 1). On the next day, they were given a further test with $\mathrm{HCl}$, being given access to $30 \mathrm{ml}$ of the solution for $30 \mathrm{~min}$ at noon. On the following day, all animals received a conditioning trial (Conditioning trial 2) on which they were given $10 \mathrm{ml}$ of the sucrose solution for $30 \mathrm{~min}$ followed immediately by an injection of $4 \mathrm{ml}$ of $\mathrm{LiCl}$. A further recovery day was followed by 2 test days (CR Test 2) on each of which the animals were given free access to the sucrose solution for 30 $\min$.

For rats in Experiment 1b, the first conditioning session consisted of access to $5 \mathrm{ml}$ of Flavor A for 5 min followed immediately by access for a further $5 \mathrm{~min}$ to a bottle containing $4 \mathrm{ml}$ of $\mathrm{LiCl}$ for the subjects in the LI-LO and SI-LO groups or $4 \mathrm{ml}$ of $\mathrm{NaCl}$ for the subjects in the SI-SO 
group. After a recovery day, the aversion established to Flavor A was tested in all animals by giving them free access to this solution for a period of 30 min (CR Test 1 in Table 1). The second conditioning trial occurred on the next day. This consisted of giving all animals access to $10 \mathrm{ml}$ of Flavor B for $30 \mathrm{~min}$, followed by an intraperitonal injection of $4 \mathrm{ml}$ of $\mathrm{LiCl}$. After a further recovery day, all then received 2 test days (CR Test 2 ) on each of which they were given free access to Flavor B for $30 \mathrm{~min}$.

\section{Results and Discussion}

Experiment 1a. No data were recorded during the preexposure phase. As we anticipated, on the basis of the results of Loy and Hall (2002), the rats (in the LI-LO and SI-LO groups) given access to the $\mathrm{LiCl}$ solution in Conditioning trial 1 drank it as readily as those (in the SI-SO group) given saline. Group mean scores were $3.8 \mathrm{ml}$ and $4.0 \mathrm{ml}$ for the LI-LO and SI-LO groups and $3.9 \mathrm{ml}$ for the SI-SO group. An analysis of variance (ANOVA) conducted on these scores showed there to be no significant difference among the groups, $F(2,21)=1.02$ (here and elsewhere a significance level of $p<.05$ was adopted). But when they were then given access to the $\mathrm{HCl}$ solution, those animals that had just drunk $\mathrm{LiCl}$ showed a reduced level of consumption compared with the animals that had just drunk saline. On this test, the SI-SO group drank 12.5 $\mathrm{ml}$, whereas the LI-LO group drank $7.3 \mathrm{ml}$ and the SI-LO group drank $6.2 \mathrm{ml}$. An ANOVA showed there to be a significant difference among the groups, $F(2,21)=18.38$. Pairwise comparisons using Tukey's test showed that the SI-SO group differed significantly from each of the other groups, which did not themselves differ. To the extent that suppression of consumption on this test provides a measure of the effectiveness of $\mathrm{LiCl}$ ingestion in producing nausea, we may conclude that the preexposure to (injections of) $\mathrm{LiCl}$ does not result in any loss of effectiveness-the suppression shown by the LI-LO group was just as marked as that shown by subjects in the SI-LO group who experienced the effects of $\mathrm{LiCl}$ for the first time on this trial. The results of the second test with $\mathrm{HCl}$, administered 2 days after the first, confirmed that the suppression shown by the LO groups was indeed an immediate response to the ingestion of $\mathrm{LiCl}$. On this trial, all of the groups drank the $\mathrm{HCl}$ solution equally readily. The mean scores were 11.0 $\mathrm{ml}$ for the LI-LO group, $10.6 \mathrm{ml}$ for the SI-LO group, and $9.2 \mathrm{ml}$ for the SI-SO group. These scores did not differ significantly, $F(2$, 21) $=3.02$.

The results for the saline consumption test are presented in the left-hand panel of Figure 1. The SI-SO group drank saline readily, but by comparison, consumption was suppressed in the other groups. An ANOVA showed there to be a significant difference among the groups, $F(2,21)=19.77$. Pairwise comparisons using Tukey's test showed that the SI-SO group differed significantly from each of the other groups; there was no significant difference between the LI-LO and SI-LO groups. The low level of consumption shown by these groups reflects the acquisition of an aversion to the flavor of salty solutions produced by their having consumed $\mathrm{LiCl}$. The critical finding for our present concern is that magnitude of the aversion was the same in the two groups. Preexposure to (injections of) $\mathrm{LiCl}$ did not attenuate the aversion shown by the LI-LO group; by this measure, therefore, there was no sign of the US-preexposure effect.

The right-hand panel of Figure 1 shows the results of the two test trials with the sucrose solution given after the animals had received a conditioning trial (reinforced by an injection of $\mathrm{LiCl}$ ) with sucrose as the CS. All groups drank somewhat less on Trial 1 than on Trial 2, consistent with their having formed an aversion to sucrose that extinguished as a result of the first test. But on both tests, more clearly on the first, the LI-LO group drank more (i.e., showed less of an aversion) than the other two groups. An ANOVA conducted on the data summarized in the figure, with group and trial as the variables, revealed a significant effect of group, $F(2,21)=15.06$, and of trial, $F(1,21)=31.33$, and a significant interaction between the variables, $F(2,21)=4.28$. An analysis of simple effects showed that there was a difference among the groups both on Trial $1, F(2,42)=11.13$, and on Trial
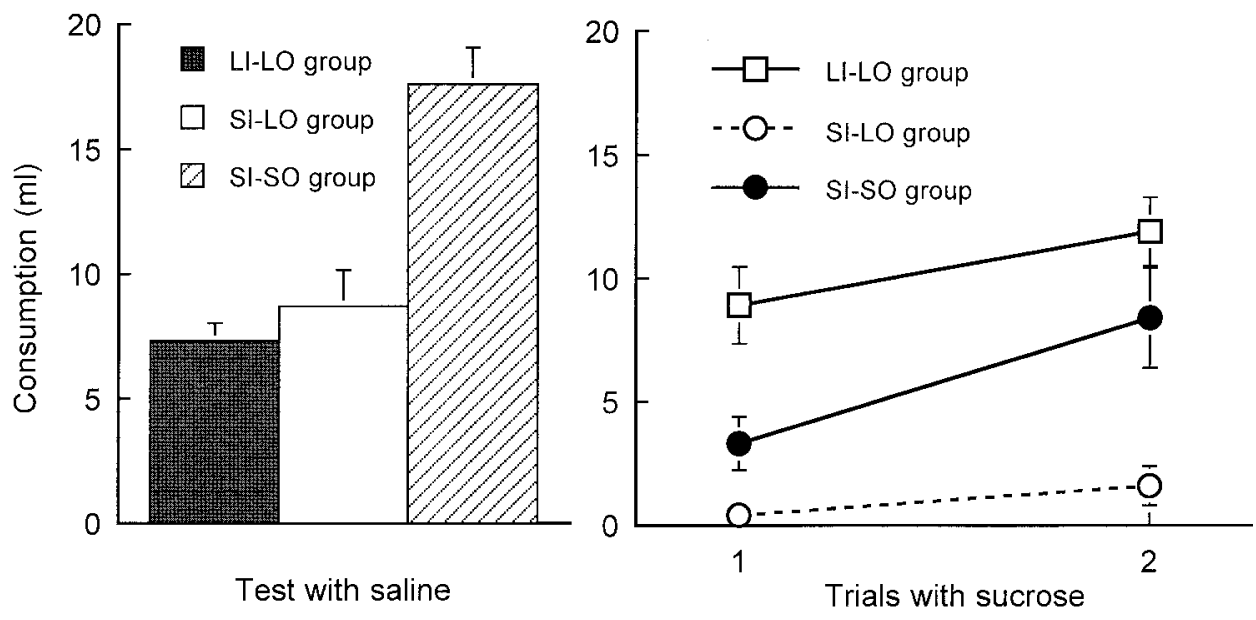

Figure 1. Experiment 1a: Group mean consumption scores for the tests with saline (given after rats in the LI-LO and SI-LO groups had drunk LiCl) and with sucrose (given after all animals had experienced sucrose followed by an injection of $\mathrm{LiCl}$ ). Rats in the $\mathrm{LI}-\mathrm{LO}$ group had received three injections of $\mathrm{LiCl}$ in the first stage of training. Vertical bars represent the standard error of the mean. $\mathrm{L}=$ lithium; $\mathrm{S}=$ saline; $\mathrm{I}=$ injected; $\mathrm{O}=$ oral administration; $\mathrm{LiCl}=$ lithium chloride. 
2, $F(2,42)=16.17$. Tukey's test showed that on Trial 1 the LI-LO group differed from each of the other two groups, which did not differ significantly from each other; on Trial 2 the LI-LO group did not differ significantly from the SI-SO group, but both differed from the SI-LO group.

These results constitute a demonstration of the US-preexposure effect in that subjects that had been given preexposure to $\mathrm{LiCl}$ (the LI-LO group) showed less of an aversion than the control groups that had not been given such preexposure. The effect was particularly marked (being significant on both test trials) when the comparison was made with the SI-LO control condition. It remains to explain, therefore, why the aversion should have been more marked in the SI-LO group than in the SI-SO group. These two groups differed only in that the former had previously drank the $\mathrm{LiCl}$ solution rather than saline. One possibility, therefore, is that the experience of nausea induced by drinking $\mathrm{LiCl}$ might have sensitized the animals in the SI-LO group making them more susceptible to the effects of the subsequent $\mathrm{LiCl}$ injection. An alternative is that the test performance of the SI-LO group may reflect the fact that these animals had previously acquired an aversion to saline. To the extent that there is generalization from saline to sucrose, the aversion formed as a result of drinking lithium might contribute to performance on the final test with sucrose and help keep levels of consumption low.

The main finding of this experiment, however, is that the overall pattern of results is consistent with the proposal that the USpreexposure effect seen here is solely a consequence of blocking by injection-related cues. Animals given a series of injections of $\mathrm{LiCl}$ during preexposure showed retarded acquisition of a flavor aversion when the US was $\mathrm{LiCl}$ administered by injection. But the aversion established in these same animals by drinking $\mathrm{LiCl}$ (and thus in the absence of injection cues) was just as strong as that shown by animals that had not received preexposure. There was no indication that either blocking by context cues or habituation to the effects of lithium contributed to the US-preexposure effect in this situation. If the preexposure phase had established a contextnausea association capable of blocking acquisition in the final phase of training, then it might be expected, because the same context was used throughout, that this association would also have been capable of blocking the aversion produced by drinking lithium. No such effect was obtained. Similarly, habituation to the effects of lithium might be expected to retard acquisition whether the US is drunk or is administered as an injection. The fact the UR evoked by drinking lithium was not attenuated by preexposure adds weight to the conclusion that the US-preexposure regime used in this experiment does not produce any marked habituation effect.

Experiment $1 \mathrm{~b}$. On the first conditioning session, all animals drank Flavor A readily. The group mean consumption scores were $4.0 \mathrm{ml}$ for the LI-LO group, $3.9 \mathrm{ml}$ for the SI-LO group, and 3.6 $\mathrm{ml}$ for the SI-SO group. These scores did not differ significantly, $F(2,21)=1.20$. The groups did differ, however, in the amount they consumed of the solution that was made available after Flavor A, $F(2,21)=17.90$. This was entirely a consequence of the fact that the group given $\mathrm{NaCl}$ drank more than those given $\mathrm{LiCl}$, which did not themselves differ. The group mean scores were 3.3 $\mathrm{ml}$ for the SI-SO group (given $\mathrm{NaCl}$ ) and $2.1 \mathrm{ml}$ for both of the other two groups. The reason for this difference among the groups is not clear (no such difference was seen in Experiment 1a).

The results of CR Test 1 (with Flavor A) are shown in the left-hand panel of Figure 2. Consumption of Flavor A was low in the LO groups, compared with the level of consumption shown by
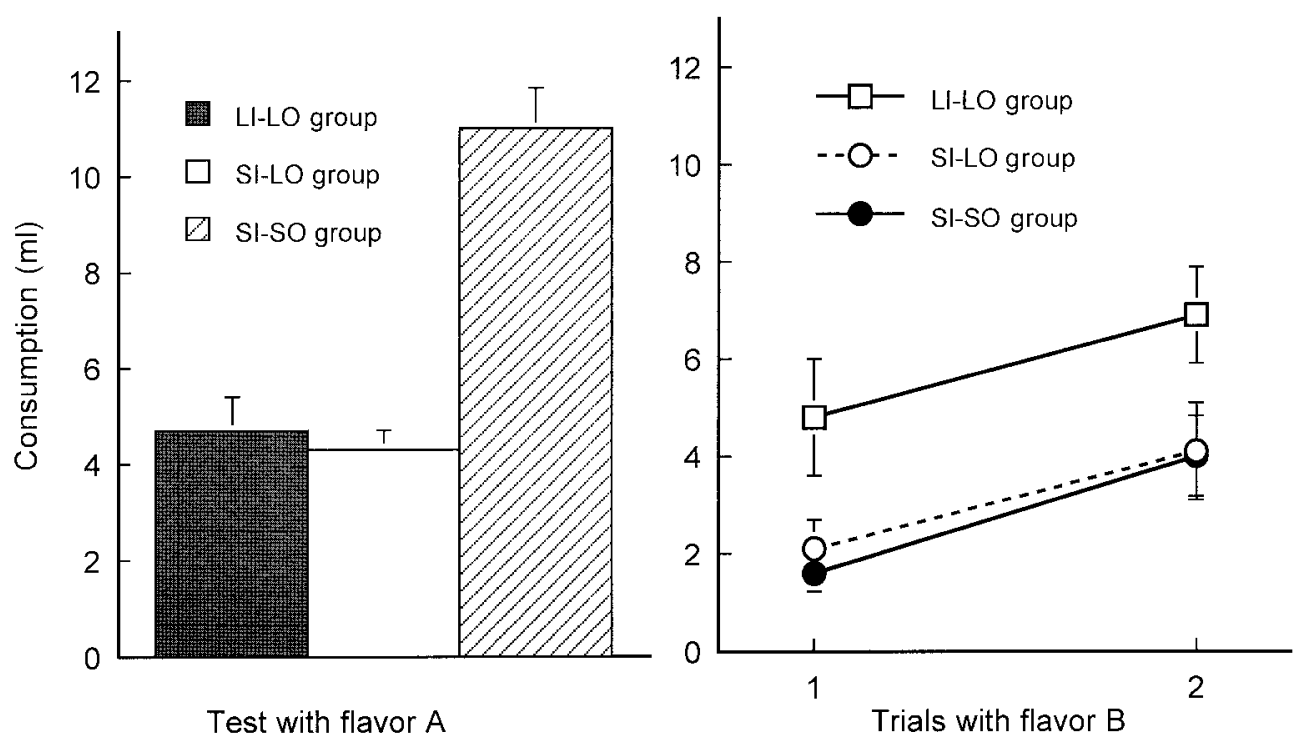

Figure 2. Experiment 1b: Group mean consumption scores for the tests with Flavor A (given after rats in the LI-LO and SI-LO groups had experienced Flavor A prior to drinking $\mathrm{LiCl}$ ) and with Flavor B (given after all animals had experienced Flavor B followed by an injection of $\mathrm{LiCl}$ ). Flavors A and B were saccharin and vinegar (counterbalanced). Rats in the LI-LO group had received three injections of $\mathrm{LiCl}$ in the first stage of training. Vertical bars represent the standard error of the mean. $\mathrm{L}=$ lithium; $\mathrm{S}=$ saline; $\mathrm{I}=$ injected; $\mathrm{O}=$ oral administration; $\mathrm{LiCl}=$ lithium chloride. 
the SI-SO group. An ANOVA showed there to be a significant difference among the groups, $F(2,21)=29.94$. Pairwise comparisons by Tukey's test showed that the SI-SO group differed from each of the other groups, which did not themselves differ reliably. We conclude that drinking Flavor A after drinking LiCl established an aversion to that flavor and that the magnitude of this aversion was quite unaffected by the prior exposure to injections of $\mathrm{LiCl}$ given to the LI-LO group.

On the second conditioning trial, all but one of the animals drank Flavor B readily. The exception (an animal in the LI-LO group) was excluded from further consideration. The mean scores for the remaining animals were $9.3 \mathrm{ml}$ for the LI-LO group, $9.1 \mathrm{ml}$ for the SI-LO group, and $8.4 \mathrm{ml}$ for the SI-SO group. These scores did not differ reliably, $F(2,20)=1.40$. The results of the test trials with Flavor B are shown on the right of Figure 2. The amount consumed increased from Trial 1 to Trial 2, but on both trials consumption was low in the control groups and was markedly higher in the LI-LO group. An ANOVA with group and trial as the variables showed there to be a significant effect of group, $F(2$, $20)=5.26$. There was also a significant effect of trial, $F(1,20)=$ 17.59. The interaction between the variables was not significant $(F<1)$. Pairwise analyses of the overall group means by Tukey's test showed that the LI-LO group differed from each of the other groups; there was no difference between the two control groups. The results of this experiment are entirely in accord with those of Experiment 1a. They show that the flavor aversion established by drinking a solution of $\mathrm{LiCl}$ is quite unaffected by prior experience of injections of $\mathrm{LiCl}$. Such preexposure, however, produces a marked attenuation of the aversion produced when US is an injection of $\mathrm{LiCl}$.

\section{Experiment 2}

Our interpretation of the results of Experiments 1 is that this version of the US-preexposure effect is a consequence of blocking by injection-related cues. During the preexposure phase, these cues acquire associative strength as signals for the aversive effects of $\mathrm{LiCl}$. When these cues are present during a subsequent conditioning trial, they act to block the acquisition of the aversion to the flavor CS; when they are absent, the ingestion of $\mathrm{LiCl}$ is fully able to establish a conditioned flavor aversion. An implication of this interpretation is that it should be possible to block aversion learning in the latter case by the introduction, on the conditioning trial, of previously conditioned injection cues. The present experiment explored this prediction.

The design of the experiment is shown in the bottom panel of Table 1. As in Experiment 1b, the LI-LO group received injections of $\mathrm{LiCl}$ in preexposure and a conditioning phase in which they drank a novel flavored solution (saccharin in this experiment) immediately before drinking the $\mathrm{LiCl}$ solution. On the basis of our previous result, we anticipated that this training would establish an aversion to saccharin. The LI-SI/LO group received the same treatment, except that they also received an injection of saline just before being given access to $\mathrm{LiCl}$ on the conditioning session. If the preexposure procedure endows injection-related cues with associative strength as signals for the effects of $\mathrm{LiCl}$, then their presence on this trial might allow them to block the acquisition of the aversion produced by drinking $\mathrm{LiCl}$; that is, a US-preexposure effect might be expected in this group. The SI-SI/LO group also received the saline injection on the conditioning trial, but these animals had not been given previous experience of injections of $\mathrm{LiCl}$ (rather they received saline injections during preexposure). For these animals, the injection cues will not have acquired associative strength, blocking should not occur, and the aversion to saccharin should be acquired, just as in the LI-LO group.

\section{Method}

The subjects were 24 experimentally naive female Wistar rats with a mean weight of approximately $200 \mathrm{~g}$ at the start of the experiment. Housing and maintenance conditions were the same as those described for Experiment $1 \mathrm{~b}$.

During the preexposure phase, subjects in the LI groups were given three intraperitoneal injections of $4 \mathrm{ml}$ of $\mathrm{LiCl}$; subjects in the SI-SI/LO group were given injections of $4 \mathrm{ml}$ of $\mathrm{NaCl}$ in this phase. On the conditioning day, all animals were first given access to $5 \mathrm{ml}$ of saccharin solution for 5 min. This drinking tube was then removed and the subjects in the LI-SI/LO and SI-SI/LO groups were given injections of $4 \mathrm{ml}$ of $\mathrm{NaCl}$; subjects in the LI-LO group were left undisturbed at this time. All were then given access to $4 \mathrm{ml}$ of $\mathrm{LiCl}$ for $5 \mathrm{~min}$. After a recovery day, all received 3 consecutive test days on each of which they were given free access to the saccharin solution for $30 \mathrm{~min}$. Procedural details not specified here were the same as those described for Experiments $1 \mathrm{a}$ and $1 \mathrm{~b}$.

\section{Results and Discussion}

On the conditioning trial, the LI-LO group drank a mean of 3.9 $\mathrm{ml}$ of the saccharin solution, the LI-SI/LO group drank $3.6 \mathrm{ml}$, and the SI-SI/LO group drank $3.7 \mathrm{ml}$. These scores did not differ significantly $(F<1)$. Nor did the groups differ in the amount of $\mathrm{LiCl}$ they drank; the corresponding group mean scores were 2.2 $\mathrm{ml}, 2.1 \mathrm{ml}$, and $1.8 \mathrm{ml}$, respectively $(F<1)$.

The results for the test trials with saccharin are presented in Figure 3. All three groups drank increasing amounts over the course of the test, presumably reflecting the extinction of an aversion acquired to saccharin. But on all three trials (most markedly on the last) the LI-SI/LO group drank somewhat more than the other two groups. An ANOVA was conducted on the data summarized in the figure, with group and trial as the variables. This revealed significant effects both of trial, $F(1,21)=182.00$, and of group, $F(2,21)=10.99$; the interaction between the variables was not significant, $F(2,21)=2.08$. The source of the difference among the groups was assessed by conducting pairwise comparisons (using Tukey's test) on the overall scores. These showed that the LI-SI/LO group differed significantly from each of the other groups, which did not themselves differ.

The absence of a difference between the LI-LO and SI-SI/LO groups confirms the findings of Experiment 1. The size of the flavor aversion established by drinking $\mathrm{LiCl}$ was the same in animals that had never experienced the effects of $\mathrm{LiCl}$ before (the SI-SI/LO group) as in animals that had had previous experience of injections of $\mathrm{LiCl}$ (the LI-LO group); that is, there was no USpreexposure effect in this case. The new results are for the LISI/LO group. These animals were treated just like those in the LI-LO group, except that injection cues were presented on the trial on which they drank the $\mathrm{LiCl}$ solution. The LI-SI/LO group showed a lesser aversion than the other two groups; that is, they showed evidence of the US-preexposure effect. We conclude that the injection cues, which had been established as a signal for the 


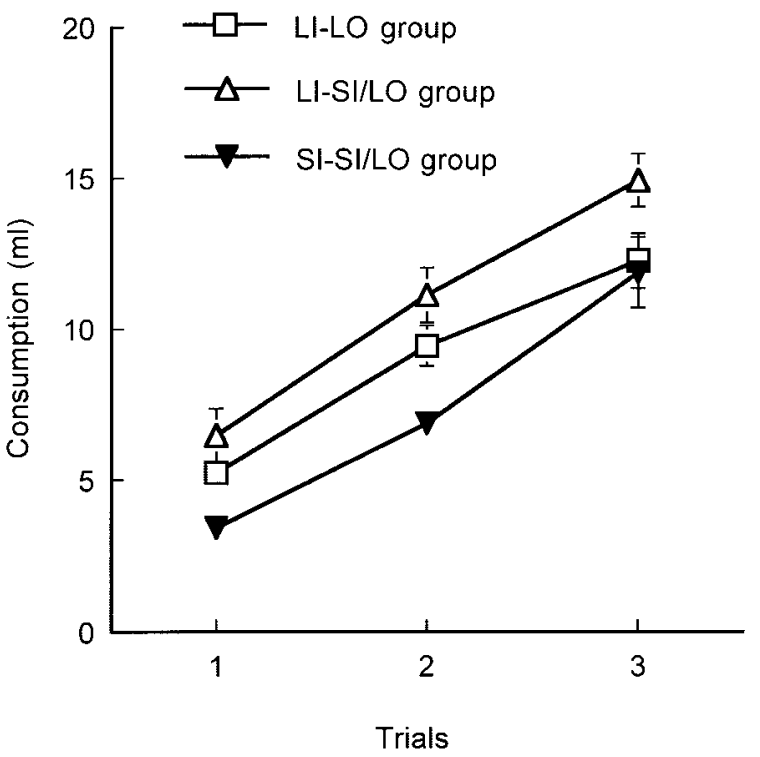

Figure 3. Experiment 3: Group mean consumption scores for the test with saccharin. All animals had previously received a conditioning trial in which they drank saccharin prior to drinking LiCl. Rats in the LI-SI/LO and SI-SI/LO groups received a saline injection on this trial. Rats in the LI-LO and LI-SI/LO groups had received three injections of $\mathrm{LiCl}$ in the first stage of training. Vertical bars represent the standard error of the mean. $\mathrm{L}=$ lithium; $\mathrm{S}=$ saline; $\mathrm{I}=$ injected; $\mathrm{O}=$ oral administration; $\mathrm{LiCl}=$ lithium chloride

effects of $\mathrm{LiCl}$ during the preexposure phase, were capable of blocking the acquisition of the aversion to saccharin produced by drinking $\mathrm{LiCl}$.

\section{General Discussion}

The US-preexposure effect demonstrated in the experiments reported here is not to be explained in terms of either habituation to the US or of blocking by contextual cues. Rats given three injections of $\mathrm{LiCl}$ showed retarded acquisition of a conditioned flavor aversion when the US was $\mathrm{LiCl}$ administered by injection, but when the US was administered by allowing the rats to drink a solution of $\mathrm{LiCl}$, the aversion was acquired as normal. If preexposure has its effects by producing habituation to the effects of lithium, then a US-preexposure effect might be expected when the lithium is drunk as when it is injected. (Further evidence against an interpretation in terms of habituation comes from the demonstration, in Experiment 1a, that the UR elicited by drinking lithium was not affected by prior experience of injections of LiCl.) Again, if the US-preexposure effect depends on the acquisition of associative strength by environmental contextual cues, then the effect might be expected to occur whether the $\mathrm{LiCl}$ US is injected or drunk, as the same contextual cues were present during preexposure and both conditioning procedures.

The hypothesis that the US-preexposure effect depends on blocking by injection-related cues can readily explain these results. During preexposure, these cues are likely to acquire associative strength as signals for the effects of $\mathrm{LiCl}$; as they are present when the US is injected, they will be able to block acquisition by the flavor $\mathrm{CS}$; but as they are absent when the $\mathrm{LiCl}$ is drunk, no blocking should occur. The results of Experiment 2 confirmed this analysis by showing that the aversion established by drinking lithium could be attenuated if cues that had previously been associated with the injection of $\mathrm{LiCl}$ were presented at the same time as the lithium solution was drunk.

Although the effects reported here appear to be explicable solely in terms of blocking by injection cues, it remains possible that in other training situations other mechanisms contribute to effects produced by preexposure to lithium. Latent inhibition may restrict the acquisition of associative strength by the contextual cues that define an animal's home cage, but there is good evidence that, when injections of $\mathrm{LiCl}$ are given in a novel context, environmental contextual cues can acquire associative strength as signals for this US (see, e.g., Rodriguez, Lopez, Symonds, \& Hall, 2000; Symonds \& Hall, 1997). It follows that such environmental cues might be able to block acquisition by a flavor CS, and an attenuated CR to the flavor should be observable, particularly if the test is given in the absence of the contextual cues responsible for the blocking effect. Evidence consistent with this possibility comes from experiments by Willner (1978), Batson and Best (1979), Domjan and Best (1980), and Dacanay and Riley (1982). All of these experiments included a condition in which rats were given injections of $\mathrm{LiCl}$ in a novel context, followed by flavor-aversion conditioning in that same context. When tested in the home cage, these rats showed only a weak aversion, weaker than that shown by rats that had received preexposure in the novel context but conditioning in the home cage. The difference between these two groups is what would be expected if the novel contextual cues had acquired strength during preexposure and thus the ability to block acquisition for the animals given conditioning in the presence of these cues. For both groups, blocking by injection cues would occur, but in the group preexposed and conditioned in the novel context, blocking by contextual cues could also contribute to the US-preexposure effect.

The contextual effects reported in the experiments just described do not challenge the conclusion (that follows from the new results reported here) that blocking by contextual (cage-related) cues plays no part in the US-preexposure effect obtained when all of the procedures are carried out in the home cage. But the experiment by Domjan and Best (1980) included a further comparison that produced results that seem to call this conclusion into question. They demonstrated the US-preexposure effect in animals given preexposure, conditioning, and the test in the home cage, but showed that this effect was attenuated in rats that were treated similarly apart from being transferred to a novel context for conditioning. If the acquisition of strength by home-cage cues plays no part in animals given home-cage preexposure, then there is no reason to expect that omitting them during conditioning would attenuate the effect of preexposure. Perhaps we must acknowledge, therefore, that in some circumstances it may be possible even for home-cage cues to become associated with the effects of a lithium injection. It should be noted, however, that Domjan and Best included a further pair of groups that were not given preexposure but simply received conditioning either in the home cage or in the novel context. The final test showed that those conditioned in the context had a stronger aversion than those conditioned in the home cage (the same pattern as was shown by the groups given US preexposure). The source of this difference is unclear, but its presence in 
both the nonpreexposed and preexposed groups suggests that the effect seen in the latter is unlikely to be a consequence of processes relevant to the usual US-preexposure effect.

If the US-preexposure effect obtained in flavor-aversion conditioning with $\mathrm{LiCl}$ is to be attributed to blocking (largely by injection cues, but also, possibly, in some circumstances, by other contextual cues), is the same true of aversions established by other substances? It has often been supposed (see, e.g., Riley \& Simpson, 2001) that the effect produced by preexposure to substances such as morphine, amphetamine, and ethanol (which are normally effective, in appropriate doses, as USs in flavor-aversion learning) is a consequence of the development of pharmacological tolerance; but because these substances are usually administered by injection, it is equally possible that the effects of preexposure to them are mediated by blocking by injection-related cues. Certainly it is well established for the case of morphine that such cues do acquire strength and can modify the nature of the UR (e.g., Siegel, Hinson, \& Krank, 1978; but see also Dacanay \& Riley, 1982); for amphetamine, there is direct evidence that procedures designed to reduce the associative strength of injection cues lead to a loss of the US-preexposure effect (Cappell \& Poulos, 1979; Poulos \& Cappell, 1979). For ethanol, however, there is evidence from experiments that manipulate the route of administration (and thus constitute a parallel to those reported here for $\mathrm{LiCl}$ ) that points to a different conclusion. Marfaing-Jallat and Le Magnen (1979) maintained rats on a diet containing ethanol for 15 days prior to conditioning in which consumption of saccharin was followed by an intraperitoneal injection of ethanol. These rats acquired a saccharin aversion less readily that control subjects that had not received preexposure (see also Berman \& Cannon, 1974). Clearly this outcome cannot be the result of blocking by injection cues (these were not present during preexposure) and has been taken to imply that this example of the US-preexposure effect is a result of the development of pharmacological tolerance (although it should be acknowledged that blocking by other contextual cues still remains a possibility).

Finally, it is appropriate to mention experimental studies of "cross tolerance"- of the effects of preexposure to one US on the effectiveness of a different US as a reinforcer in flavor-aversion learning-as in several of these studies the different USs are administered by different routes, thus allowing an assessment of the role played by cues associated with US administration. For example, Hunt and Rabin (1988; see also Rabin, Hunt, \& Lee, 1989) gave rats exposure to ethanol administered by gastric intubation prior to conditioning in which consumption of saccharin was followed by irradiation. The attenuated aversion found with this procedure has been taken to indicate that the development of tolerance to one nausea-inducing event will transfer to another. It should be noted, however, that both intubation and irradiation involve subjecting the animal to handling and restraint, leaving open the possibility that the US-preexposure effect obtained with these procedures is dependent on blocking by the, presumably salient, cues that these procedures hold in common. One study that evades this ambiguity is that reported by Opitz, Mothes, and Clausing (1997) on cross tolerance between ethanol and LiCl. In this study, the conditioning phase involved oral intubation of $\mathrm{LiCl}$ given after the subjects (mice) had consumed saccharin. Preexposure to ethanol involved no handling cues, as it was arranged by allowing mothers access to ethanol while they were pregnant with the pups that were to be the subjects in the conditioning phase of the experiment. Under these circumstances, it is difficult to see how the attenuation of aversion learning ultimately observed could be a result of any form of conditioning to contextual cues present during both the preexposure and aversion learning phases of the experiment.

We have discussed three possible sources of the USpreexposure effect in flavor-aversion learning-habituation (or the development of tolerance) to the US, blocking by environmental contextual cues present during preexposure and conditioning, and blocking by injection-related cues present during preexposure and conditioning. Our final discussion has acknowledged that blocking by contextual cues may sometimes contribute to the effect produced with $\mathrm{LiCl}$ as the US. It has also described evidence to suggest that at least for some substances (such as ethanol) the effect may derive, at least in part, from the development of tolerance. Future research might be directed toward investigating the factors that determine the relative strengths of these various processes and the ways in which they might interact. But we should conclude by restating the major implication of the new results reported here: When US preexposure consists of injections of $\mathrm{LiCl}$ given in the home cage, there is no evidence that either habituation or conditioning to environmental contextual cues plays any role in the US-preexposure effect that results. Rather the effect obtained in these circumstances is entirely to be explained in terms of blocking by injection-related cues.

\section{References}

Batson, J. D. (1983). Effects of repeated lithium injections on temperature, activity, and flavor conditioning in rats. Animal Learning \& Behavior, 11, 199-204

Batson, J. D., \& Best, P. J. (1979). Drug-preexposure effects in flavoraversion learning: Associative interference by conditioned environmental stimuli. Journal of Experimental Psychology: Animal Behavior Processes, 5, 273-283.

Berman, R. F., \& Cannon, D. S. (1974). The effect of prior ethanol experience on ethanol-induced saccharin aversions. Physiology \& Behavior, 12, 1041-1044.

Braveman, N. S. (1978). The role of handling cues in the treatment preexposure effect in taste aversion learning. Bulletin of the Psychonomic Society, 12, 74-76.

Braveman, N. S., \& Jarvis, P. S. (1978). Independence of neophobia and taste aversion learning. Animal Learning \& Behavior, 6, 406-412.

Brugada, I., \& Aguado, L. (2000). El efecto de preexposición al EI en la aversión gustativa condicionada: Papel relativo del contexto y de las claves de inyección [The effect of preexposure to the US in flavoraversion conditioning: The role of context and injection cues]. Psicológica, 21, 23-37.

Brugada, I., González, F., \& Cándido, A. (2003a). Repeated administration of $\mathrm{LiCl}$ produces an unconditioned stimulus preexposure effect in backward excitatory CTA but not habituation of the unconditioned increment in neophobia. Behavioural Processes, 60, 227-233.

Brugada, I., González, F., \& Cándido, A. (2003b). The role of injection cues in the associative control of the US preexposure effect in flavour aversion learning. Quarterly Journal of Experimental Psychology: Comparative and Physiological Psychology, 56B, 241-252.

Cappell, H., \& Poulos, C. X. (1979). Associative factors in drug pretreatment effects on gustatory conditioning: Cross-drug effects. Psychopharmacology, 64, 209-213.

Dacanay, R. J., \& Riley, A. L. (1982). The UCS preexposure effect in taste 
aversion learning: Tolerance and blocking are drug specific. Animal Learning \& Behavior, 10, 91-96.

Domjan, M. (1977). Attenuation and enhancement of neophobia for edible substances. In L. M. Barker, M. R. Best, \& M. Domjan (Eds.), Learning mechanisms in food selection (pp. 151-179). Waco, TX: Baylor University Press.

Domjan, M., \& Best, M. R. (1980). Interference with ingestional learning produced by preexposure to the unconditioned stimulus: Associative and nonassociative aspects. Learning and Motivation, 11, 522-537.

Hunt, W. A., \& Rabin, B. M. (1988). Attenuation of a radiation-induced conditioned taste aversion after the development of ethanol tolerance. Life Sciences, 43, 59-66.

Kamin, L. J. (1969). Predictability, surprise, attention, and conditioning. In B. A. Campbell \& R. M. Church (Eds.), Punishment and aversive behavior (pp. 279-296). New York: Appleton-Century-Crofts.

Loy, I., \& Hall, G. (2002). Taste aversion after ingestion of lithium chloride: An associative analysis. Quarterly Journal of Experimental Psychology: Comparative and Physiological Psychology, 55B, 365-380.

Marfaing-Jallat, P., \& Le Magnen, J. (1979). Ethanol-induced taste aversion in ethanol-dependent and normal rats. Behavioral and Neural Biology, 26, 106-114.

Opitz, B., Mothes, H. K., \& Clausing, P. (1997). Effects of prenatal ethanol exposure and early experience on radial maze performance and conditioned taste aversion in mice. Neurotoxicology and Teratology, 19, 185-190.

Poulos, C. X., \& Cappell, H. (1979). An associative analysis of pretreatment effects in gustatory conditioning by amphetamine. Psychopharmacology, 64, 201-206.

Rabin, B. M., Hunt, W. A., \& Lee, J. (1989). Attenuation and crossattenuation in taste aversion learning in the rat: Studies with ionizing radiation, lithium chloride and ethanol. Pharmacology, Biochemistry \& Behavior, 31, 909-918.

Randich, A., \& LoLordo, V. M. (1979). Associative and nonassociative theories of the UCS preexposure phenomenon: Implications for Pavlovian conditioning. Psychological Bulletin, 86, 523-548.

Riley, A. L., \& Simpson, G. R. (2001). The attenuating effects of drug preexposure on taste aversion conditioning: Generality, experimental parameters, underlying mechanisms, and implications for drug use and abuse. In R. R. Mowrer \& S. B. Klein (Eds.), Handbook of contemporary learning theories (pp. 505-559). Mahwah, NJ: Erlbaum.

Rodriguez, M., Lopez, M., Symonds, M., \& Hall, G. (2000). Lithiuminduced context aversion in rats as a model of anticipatory nausea in humans. Physiology \& Behavior, 71, 571-579.

Rudy, J. W., Iwens, J., \& Best, P. J. (1977). Pairing novel exteroceptive cues and illness reduces illness-induced taste aversions. Journal of Experimental Psychology: Animal Behavior Processes, 3, 14-25.

Siegel, S., Hinson, R. E., \& Krank, M. D. (1978). The role of predrug signals in morphine analgesic tolerance: Support for a Pavlovian conditioning model of tolerance. Journal of Experimental Psychology: Animal Behavior Processes, 4, 188-196.

Symonds, M., \& Hall, G. (1997). Contextual conditioning with lithiuminduced nausea as the US: Evidence from a blocking procedure. Learning and Motivation, 28, 200-215.

Willner, J. A. (1978). Blocking of a taste aversion by prior pairings of exteroceptive stimuli with illness. Learning and Motivation, 9, 125-140.

Received June 3, 2003

Revision received August 21, 2003

Accepted September 11, 2003

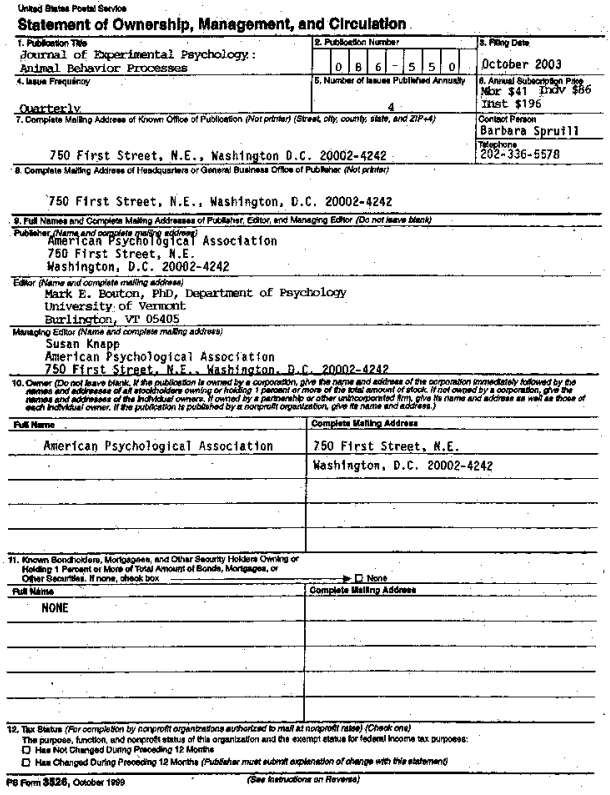

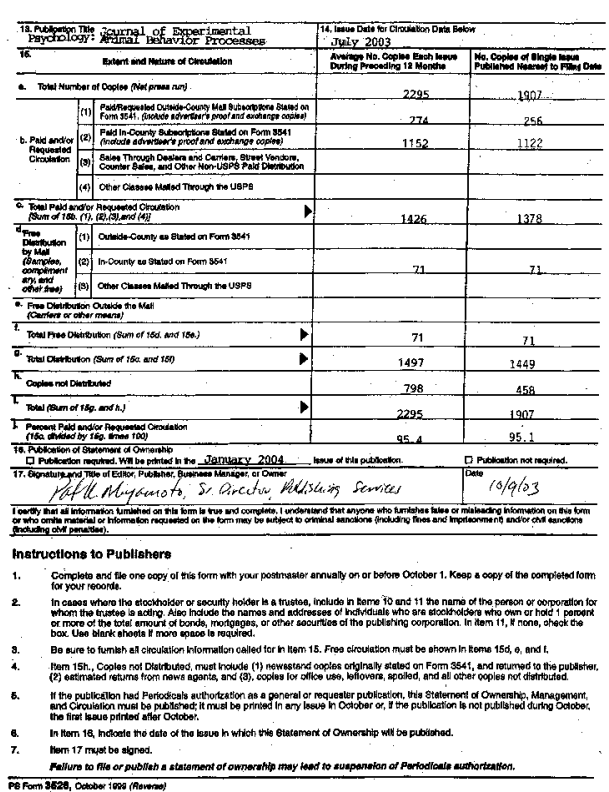

